\title{
Cold ischemia $>4$ hours increases heart transplantation mortality. An analysis of the Spanish heart transplantation registry
}

\author{
María Jesús Valero-Masa ${ }^{\mathrm{a}, \mathrm{b}}$, Francisco González-Vílchez ${ }^{\mathrm{c}}$, Luis Almenar-Bonet ${ }^{\mathrm{d}}$, Maria G. Crespo-Leiro ${ }^{\text {b,e }}$, \\ Nicolás Manito-Lorite ${ }^{\mathrm{f}}$, Jose Manuel Sobrino-Márquez ${ }^{\mathrm{g}}$, Manuel Gómez-Bueno ${ }^{\mathrm{b}, \mathrm{h}}$, Juan F. Delgado-Jiménez ${ }^{\text {b,i }}$, \\ Félix Pérez-Villa ${ }^{\mathrm{j}}$, Vicens Brossa Loidi ${ }^{\mathrm{k}}$, José María Arizón-el Prado ${ }^{1}$, Beatriz Díaz Molina ${ }^{\mathrm{m}}$, \\ Luis de la Fuente-Galán ${ }^{\mathrm{b}, \mathrm{n}}$, Ana Portoles Ocampo ${ }^{\circ}$, Iris P. Garrido Bravo ${ }^{\mathrm{b}, \mathrm{p}}$,
} Gregorio Rábago-Juan Aracil q ${ }^{\mathrm{q}}$, Manuel Martínez-Sellés a,b,r,*,1

a Cardiology Department, Hospital General Universitario Gregorio Marañón, Madrid, Spain

b Centro de Investigación Biomédica en Red de Enfermedades Cardiovasculares (CIBERCV), Instituto de Salud Carlos III, Madrid. Spain

c Cardiology Department, Hospital Universitario Marques de Valdecilla, Santander, Spain

d Cardiology Department, Hospital Universitarii i Politècnic La Fe, Valencia, Spain

e Cardiology Department, Complexo Hospitalario Universitario A Coruña, A Coruña, Spain

${ }^{\mathrm{f}}$ Cardiology Department, Hospital Universitario de Bellvitge. L'Hospitalet del Llobregat, Barcelona, Spain

${ }^{g}$ Cardiology Department, Hospital Universitario Virgen del Rocío, Sevilla, Spain

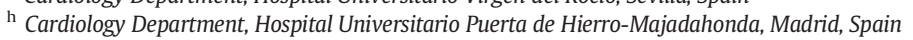

i Cardiology Department, Fundación Investigación Hospital Universitario 12 de Octubre, Facultad de Medicina, UCM, Madrid, Spain

${ }^{j}$ Cardiology Department, Hospital Clinic Universitari, Barcelona, Spain

k Cardiology Department, Hospital Universitari Santa Creu i Sant Pau, Barcelona, Spain

${ }^{1}$ Cardiology Department, Hospital Universitario Reina Sofía, Córdoba, Spain

${ }^{\mathrm{m}}$ Cardiology Department, Hospital Universitario Central de Asturias, Oviedo, Spain

n Cardiology Department, Hospital Clínico Universitario de Valladolid, Spain

${ }^{\circ}$ Cardiology Department, Hospital Universitario Miguel Servet, Zaragoza, Spain

p Cardiology Department, Hospital Universitario Virgen de la Arrixaca, Murcia, Spain

${ }^{q}$ Department of Cardiovascular Surgery, Clinica Universitaria de Navarra, Pamplona, Spain

${ }^{\mathrm{r}}$ Universidad Europea, Universidad Complutense, Madrid, Spain

\section{A R T I C L E I N F O}

\section{Article history:}

Received 14 April 2020

Received in revised form 18 May 2020

Accepted 9 June 2020

Available online $\mathrm{xxxx}$

\section{Keywords:}

Heart transplant

Ischemic time

Donor selection

\begin{abstract}
A B S T R A C T
Background: Cold ischemia time (CIT) has been associated to heart transplantation (HT) prognosis. However, there is still uncertainty regarding the CIT cutoff value that might have relevant clinical implications.

Methods: We analyzed all adults that received a first HT during the period 2008-2018. CIT was defined as the time between the cross-clamp of the donor aorta and the reperfusion of the heart. Primary outcome was 1-month mortality.

Results: We included 2629 patients, mean age was $53.3 \pm 12.1$ years and $655(24.9 \%)$ were female. Mean CIT was $202 \pm 67$ min (minimum 20 min, maximum $600 \mathrm{~min}$ ). One-month mortality per CIT quartile was 9, 12, 13, and $19 \%$. One-year mortality per CIT quartile was 16, 19, 21, and 28\%. CIT was an independent predictor of 1-month mortality, but only in the last quartile of CIT $>246$ min (odds ratio $2.1,95 \%$ confidence interval 1.49-3.08, $p<.001$ ). We found no relevant differences in CIT during the study period. However, the impact of CIT in 1 -month and 1-year mortality decreased with time ( $p$ value for the distribution of ischemic time by year 0.01 ), particularly during the last 5 years.

Conclusions: Although the impact of CIT in HT prognosis seems to be decreasing in the last years, CIT in the last quartile ( $>246 \mathrm{~min}$ ) is associated with 1-month and 1-year mortality. Our findings suggest the need to limit HT with CIT $>246$ min or to use different myocardial preservation systems if the expected CIT is $>4 \mathrm{~h}$.
\end{abstract}

(c) 2020 Elsevier B.V. All rights reserved.

\footnotetext{
* Corresponding author at: Cardiology Department, Hospital General Universitario Gregorio Marañón, Calle Doctor Esquerdo, 46, 28007 Madrid, Spain. E-mail address: mmselles@secardiologia.es (M. Martínez-Sellés).

${ }^{1}$ This author takes responsibility for all aspects of the reliability and freedom from bias of the data presented and their discussed interpretation.
} 


\section{Introduction}

Heart transplantation (HT) is the treatment of choice for carefully selected patients with advanced or end-stage heart failure [1], with a median survival around 12 years. Among the different factors that may influence the prognosis of HT [2], cold ischemia time (CIT) has been associated with primary graft failure and mortality [3] and is one of the most important risk factors for early graft dysfunction [4]. However, there is still uncertainty regarding the CIT cutoff value that might have relevant clinical implications. The recent changes in HT have included an increase in donors and recipients age, in the rate of emergent transplantation, and, according to some data, of CIT [5]. Yet, this change has not been associated with higher mortality [6]. Although different strategies have been developed in order to expand the pool of donors, including donationafter-circulatory-death and TransMedics ${ }^{\circledR}$ Organ Care System [7] the vast majority of HT are done with hearts preserved in cold systems [8].

Table 1

Baseline characteristics according to cold ischemia time (CIT) quartile.

\begin{tabular}{|c|c|c|c|c|c|}
\hline \multirow[t]{3}{*}{ Characteristic } & \multicolumn{4}{|c|}{ Ischemic time quartiles } & \multirow[t]{3}{*}{$p$-value } \\
\hline & \multirow{2}{*}{$\begin{array}{l}\leq 159 \min \\
\text { Mean } \pm \text { SD or } \\
\text { no. }(\%)(n=664)\end{array}$} & \multirow{2}{*}{$\begin{array}{l}\frac{160-210 \mathrm{~min}}{\mathrm{Mean} \pm \mathrm{SD} \text { or }} \\
\text { no. }(\%)(n=724)\end{array}$} & \multirow{2}{*}{$\begin{array}{l}211-246 \mathrm{~min} \\
\text { Mean } \pm \text { SD or } \\
\text { no. }(\%)(n=591)\end{array}$} & \multirow{2}{*}{$\begin{array}{l}>246 \text { min } \\
\text { Mean } \pm \text { SD or } \\
\text { no. }(\%)(n=650)\end{array}$} & \\
\hline & & & & & \\
\hline \multicolumn{6}{|l|}{ A) Recipients } \\
\hline Age. mean \pm SD & $53.8 \pm 11.8$ & $53.7 \pm 11.2$ & $52.8 \pm 12.3$ & $52.6 \pm 12.4$ & 0.326 \\
\hline Sex (males) & $503(75.8)$ & $552(76.2)$ & $425(71.9)$ & $494(76.0)$ & 0.632 \\
\hline BMI. mean \pm SD & $25.5 \pm 3.91$ & $25.5 \pm 4.13$ & $25.4 \pm 3.92$ & $25.8 \pm 4.18$ & 0.224 \\
\hline \multicolumn{6}{|l|}{ Cardiomyopathy } \\
\hline Nonischemic dilated cardiomyopathy & $268(40.4)$ & $280(38.7)$ & $234(39.6)$ & $226(34.8)$ & 0.558 \\
\hline Ischemic dilated cardiomyopathy & $181(27.3)$ & $214(29.6)$ & $168(28.4)$ & $226(34.8)$ & \\
\hline Valvular & $39(5.9)$ & $36(5.0)$ & $41(6.9)$ & $44(6.8)$ & \\
\hline Others & $176(26.5)$ & $194(26.8)$ & $148(25.0)$ & $154(23.7)$ & \\
\hline PVR (UW). mean \pm SD & $2.2 \pm 1.2$ & $2.3 \pm 1.5$ & $2.3 \pm 1.7$ & $2.1 \pm 1.3$ & 0.130 \\
\hline Creatinine $>2 \mathrm{mg} / \mathrm{dl}$ & $30(4.5)$ & $39(5.4)$ & $23(3.9)$ & $36(5.6)$ & 0.667 \\
\hline Bilirubin >2 mg/dl & $116(18.9)$ & $109(16.4)$ & $89(16.4)$ & $103(17.6)$ & 0.541 \\
\hline Diabetes mellitus & $135(20.5)$ & $149(20.7)$ & $126(21.4)$ & $146(22.7)$ & 0.308 \\
\hline COPD moderate-severe & $68(11.2)$ & $81(12.0)$ & $59(10.4)$ & $57(8.9)$ & 0.130 \\
\hline Previous infection & $69(10.4)$ & $93(12.9)$ & $93(15.7)$ & $124(19.2)$ & $<0.001$ \\
\hline Previous thoracic surgery & $142(21.5)$ & $187(25.9)$ & $181(31.0)$ & $226(34.9)$ & $<0.001$ \\
\hline Urgent transplant & $186(28.0)$ & $271(37.4)$ & $287(48.6)$ & $311(47.9)$ & $<0.001$ \\
\hline Mechanical ventilation prior to transplant & $63(9.6)$ & $77(10.7)$ & $107(18.1)$ & $138(21.5)$ & $<0.001$ \\
\hline \multicolumn{6}{|l|}{ VAD prior to $\mathrm{HT}$} \\
\hline No & $490(74.4)$ & $480(67.0)$ & $337(57.2)$ & $368(57.0)$ & $<0.001$ \\
\hline IABP & $62(9.4)$ & $89(12.4)$ & $89(15.1)$ & $89(14.7)$ & \\
\hline ECMO & $47(7.1)$ & $52(7.3)$ & $61(10.4)$ & $67(10.4)$ & \\
\hline Continuous flow-VAD & $47(7.1)$ & $79(11.0)$ & $74(12.6)$ & $82(12.7)$ & \\
\hline Pulsatile flow-VAD & $13(2.0)$ & $16(2.2)$ & $28(4.8)$ & $34(5.3)$ & \\
\hline \multicolumn{6}{|l|}{ B) Donor } \\
\hline Age. mean \pm SD & $43.8 \pm 12.5$ & $43.2 \pm 12.5$ & $43.4 \pm 12.6$ & $42.1 \pm 12.7$ & 0.085 \\
\hline Sex (males) & $408(61.54)$ & $447(61.7)$ & $369(62.5)$ & $440(67.7)$ & 0.023 \\
\hline Female donor/male recipient & $163(24.6)$ & $169(23.3)$ & $117(19.8)$ & $125(19.2)$ & 0.007 \\
\hline Weight. mean \pm SD & $77.1 \pm 14.4$ & $76.3 \pm 13.8$ & $76.4 \pm 13.3$ & $77.1 \pm 14.3$ & 0.581 \\
\hline Weight recipient/donor $>1.20$ & $57(8.7)$ & $72(10.0)$ & $41(7.0)$ & $71(10.9)$ & 0.453 \\
\hline Weight recipient/donor $<0.8$ & $123(18.7)$ & $118(16.3)$ & $106(18.0)$ & $112(17.2)$ & 0.683 \\
\hline \multicolumn{6}{|l|}{ Cause of death } \\
\hline Cerebrovascular & 395(59.6) & $405(56.1)$ & $336(57.1)$ & $366(56.8)$ & 0.265 \\
\hline Traumatism & $167(25.2)$ & $205(28.4)$ & $150(25.5)$ & $165(25.6)$ & \\
\hline Others & $101(15.2)$ & $112(15.5)$ & 103(17.5) & $113(17.6)$ & \\
\hline \multicolumn{6}{|l|}{ C) Complications and mortality } \\
\hline Primary graft failure & $125(19.2)$ & $159(22.3)$ & $128(22.5)$ & $184(29.5)$ & $<0.001$ \\
\hline ICU stay length & $9.7 \pm 11.5$ & $10.6 \pm 13$ & $12.4 \pm 15.1$ & $11.9 \pm 16.2$ & $<0.001$ \\
\hline CAV & $56(8.4)$ & $74(10.2)$ & $48(8.1)$ & $49(7.5)$ & 0.337 \\
\hline Infection & $231(38.8)$ & $259(39.4)$ & $206(40.5)$ & $189(33.9)$ & 0.148 \\
\hline Hypertension & $232(40.0)$ & $278(44.7)$ & $200(39.7)$ & $238(43.8)$ & 0.495 \\
\hline \multicolumn{6}{|l|}{ Diabetes } \\
\hline No & $370(66.5)$ & $411(66.4)$ & $332(66.7)$ & $357(66.9)$ & 0.769 \\
\hline Diet & $10(1.8)$ & $14(2.3)$ & $17(3.4)$ & $15(2.8)$ & \\
\hline Oral antidiabetics & $47(8.3)$ & $56(9.1)$ & $45(9.0)$ & $40(7.5)$ & \\
\hline Insulin & $134(23.5)$ & $138(22.3)$ & $104(20.9)$ & $122(22.9)$ & \\
\hline Neurologic disease & $60(10.4)$ & $91(14.6)$ & $87(17.4)$ & $104(19.2)$ & $<0.001$ \\
\hline Renal replacement therapy & $38(6.7)$ & $50(8.1)$ & $42(8.4)$ & $56(10.4)$ & 0.030 \\
\hline Permanent pacemaker & $31(5.6)$ & $31(5.2)$ & $22(4.6)$ & $15(2.9)$ & 0.034 \\
\hline 1-month mortality & $58(8.7)$ & $86(11.9)$ & $74(12.5)$ & $121(18.6)$ & $<0.001$ \\
\hline 1-year mortality & $104(15.7)$ & $140(19.3)$ & $125(21.2)$ & $179(27.5)$ & $<0.001$ \\
\hline
\end{tabular}

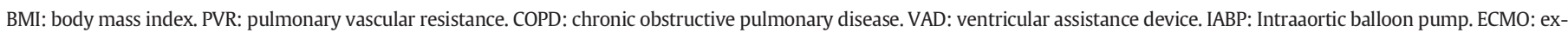
tracorporeal membrane oxygenation.

ICU: Intensive care unit. CAV: Cardiac Allograft Vasculopathy. 
Table 2

Univariate and multivariate logistic regression analysis for A) 1-month mortality and B) 1-year mortality.

\begin{tabular}{|c|c|c|c|}
\hline & OR $(95 \% \mathrm{CI})$ & p-value & $\%$ missing \\
\hline \multicolumn{4}{|l|}{ A } \\
\hline Ischemic time & \multirow{2}{*}{\multicolumn{2}{|c|}{$1.00(1.00-1.01)$}} & 0.49 \\
\hline Recipient data & & & \\
\hline Age & $1.00(0.99-1.01)$ & 0.565 & 0.00 \\
\hline Sex (Female) & $1.18(0.92-1.52)$ & 0.197 & 0.00 \\
\hline BMI & $1.00(0.98-1.03)$ & 0.750 & 0.11 \\
\hline \multicolumn{4}{|l|}{ Cardiomyopathy } \\
\hline \multicolumn{4}{|l|}{ Nonischemic dilated cardiomyopathy } \\
\hline Ischemic dilated cardiomyopathy & $1.12(0.85-1.49)$ & 0.423 & \multirow[t]{3}{*}{0.00} \\
\hline Valvular & $1.49(0.94-2.35)$ & 0.087 & \\
\hline Others & $1.22(0.92-1.63)$ & 0.172 & \\
\hline Kidney failure & $1.44(1.12-1.86)$ & $<0.01$ & 3.10 \\
\hline Creatinine & $1.12(0.97-1.31)$ & 0.133 & 0.45 \\
\hline Bilirubin $>2 \mathrm{mg} / \mathrm{dl}$ & $1.74(1.31-2.30)$ & $<0.01$ & 8.52 \\
\hline PVR & $1.08(1.00-1.17)$ & 0.046 & 16.24 \\
\hline Previous infection & $1.81(1.36-2.40)$ & $<0.01$ & 0.23 \\
\hline Diabetes Mellitus & $0.97(0.73-1.28)$ & 0.824 & 0.64 \\
\hline COPD moderate-severe & $1.10(0.76-1.60)$ & 0.598 & 5.19 \\
\hline Mechanical ventilation & $2.50(1.91-3.27)$ & $<0.01$ & 0.79 \\
\hline VAD prior to HT & $1.38(1.10-1.74)$ & $<0.01$ & 0.72 \\
\hline Previous thoracic surgery & $1.41(1.11-1.80)$ & $<0.01$ & 0.64 \\
\hline Emergency level (emergent/elective) & $0.70(0.56-0.88)$ & $<0.01$ & 0.00 \\
\hline Donor data & & & \\
\hline Age & $1.01(1.00-1.02)$ & 0.175 & 0.08 \\
\hline Sex (Female) & $1.00(0.79-1.26)$ & 0.967 & 0.08 \\
\hline Cause of death & & & \\
\hline Cerebrovascular & & & \\
\hline Traumatism & $1.03(0.79-1.34)$ & 0.813 & 0.45 \\
\hline Others & $0.8580 .61-1.18)$ & 0.332 & \\
\hline & Multiva & & p-value \\
\hline 1-month mortality & & & \\
\hline Cold ischemia time & & & \\
\hline $1-\leq 159 \min$ & 1 & & \\
\hline $2-160-210 \mathrm{~min}$ & $1.37(0$ & & 0.11 \\
\hline $3-211-246 \mathrm{~min}$ & $1.33(0$ & & 0.15 \\
\hline $4->246 \min$ & $2.14(1$ & & $<0.01$ \\
\hline Transplant year & $0.94(0$ & & $<0.01$ \\
\hline Kidney failure & $1.42(1$ & & 0.01 \\
\hline Bilirubin $\geq 2 \mathrm{mg} / \mathrm{dl}$ & $1.55(1$ & & $<0.01$ \\
\hline Mechanical ventilation & $2.24(1$ & & $<0.01$ \\
\hline Previous thoracic surgery & $1.37(1$ & & 0.02 \\
\hline & OR $(95 \% \mathrm{CI})$ & p-value & $\%$ missing \\
\hline B & & & \\
\hline Ischemic time & $1.00(1.00-1.01)$ & $<0.01$ & 0.49 \\
\hline Recipient data & & & \\
\hline Age & $1.01(1.00-1.02)$ & $<0.01$ & 0.00 \\
\hline Sex (Female) & $1.17(0.95-1.45)$ & 0.142 & 0.00 \\
\hline BMI & $1.02(0.99-1.04)$ & 0.129 & 0.11 \\
\hline Cardiomyopathy & & & \\
\hline Nonischemic dilated cardiomyopath & & & \\
\hline Ischemic dilated cardiomyopathy & $1.08(0.86-1.36)$ & 0.524 & 0.00 \\
\hline Valvular & $1.27(0.86-1.88)$ & 0.227 & \\
\hline Others & $1.12(0.88-1.43)$ & 0.345 & \\
\hline Kidney failure & $1.62(1.31-2.00)$ & $<0.01$ & 3.10 \\
\hline Creatinine & $1.32(1.12-1.55)$ & $<0.01$ & 0.45 \\
\hline Bilirubin $>2 \mathrm{mg} / \mathrm{dl}$ & $1.69(1.33-2.14)$ & $<0.01$ & 8.52 \\
\hline PVR & $1.05(0.98-1.13)$ & 0.155 & 16.24 \\
\hline Previous infection & $1.82(1.43-2.32)$ & $<0.01$ & 0.23 \\
\hline Diabetes Mellitus & $1.10(0.88-1.38)$ & 0.406 & 0.64 \\
\hline COPD moderate-severe & $1.15(0.85-1.55)$ & 0.374 & 5.19 \\
\hline Mechanical ventilation & $2.39(1.89-3.02)$ & $<0.01$ & 0.79 \\
\hline VAD prior to HT & $1.50(1.24-1.82)$ & $<0.01$ & 0.72 \\
\hline Previous thoracic surgery & $1.31(1.07-1.61)$ & $<0.01$ & 0.64 \\
\hline Emergency level (emergent/elective) & $0.65(0.65-0.78)$ & $<0.01$ & 0.00 \\
\hline Donor data & & & \\
\hline Age & $1.00(1.00-1.01)$ & 0.220 & 0.08 \\
\hline Sex (Female) & $0.97(0.80-1.18)$ & 0.764 & 0.08 \\
\hline Cause of death & & & \\
\hline 1-Cerebrovascular & & & \\
\hline 2-Traumatism & $1.01(0.81-1.26)$ & 0.937 & 0.45 \\
\hline
\end{tabular}


Table 2 (continued)

\begin{tabular}{|c|c|c|c|}
\hline & OR $(95 \% \mathrm{Cl})$ & $\mathrm{p}$-value & $\%$ missing \\
\hline \multicolumn{4}{|l|}{ B } \\
\hline 3- Others & $0.83(0.63-1.09)$ & 0.186 & \\
\hline \multicolumn{4}{|l|}{ 1-year mortality } \\
\hline $1-\leq 159 \min$ & 1 & & \\
\hline $4->246 \min$ & $1.83(1$ & & $<0.01$ \\
\hline Transplant year & $0.95(C$ & & $<0.01$ \\
\hline Recipient age & $1.01(1$ & & 0.02 \\
\hline Kidney failure & $1.57(1$ & & $<0.01$ \\
\hline Bilirubin $\geq 2 \mathrm{mg} / \mathrm{dl}$ & $1.55(1$ & & $<0.01$ \\
\hline Mechanical ventilation & $2.21(1$ & & $<0.01$ \\
\hline Previous thoracic surgery & $1.31(1$ & & 0.02 \\
\hline
\end{tabular}

Kidney failure: creatinine $>2 \mathrm{mg} / \mathrm{dl}$. PVR: Pulmonary Vascular Resistance. VAD: Ventricular assist device (includes ECMO). OR: odds ratio. CI: confidence interval.

The aim of our study was to examine, in a large National consecutive $\mathrm{HT}$ registry, the trend of CIT in the last decade, as well as its influence on 30-day and 1-year.

\section{Methods}

\subsection{Population and data collection}

Our data come from the Spanish Heart Transplantation Registry, a prospective database promoted by the Working Group in Heart Failure of the Spanish Society of Cardiology that contains detailed clinical information about all HT performed in our nation. The registry is updated in a yearly basis with data supplied by all HT centers of the country. This database has been described elsewhere [6]. For the purpose of this study, data regarding CIT, baseline recipient characteristics, donor, surgical procedure, and survival were obtained from the database.

\subsection{Study population}

This was a retrospective analysis involving recipients from 17 participating centers who fulfilled the following inclusion criteria: 1) Recipient of a first isolated HT between January 2008 and November 2018; 2) Age at transplant $>16$ years; 3 ) Information of CIT available. CIT was defined as the time between the cross-clamp of the donor aorta and the reperfusion of the heart. The Spanish system tries to minimize the distance between donor and recipient but also prioritizes emergencies. First level emergencies have National priority.

The study was conducted according to the guidelines of the Declaration of Helsinki and was approved by the Ethics Committees of all the participating centers.

\subsection{Statistical analysis}

Data are presented as median with interquartile range (IQR) for continuous variables and frequency with percentage for categorical variables. Comparison between groups was conducted by use of MannWhitney U analysis. Categorical variables were compared by using $\chi 2$ or Fisher exact tests. Association between variables was assessed by using linear regression analysis and correlation by means of the nonparametric Spearman rho. CIT quartiles were used to assess the influence of CIT in prognosis. The primary outcome was 1-month mortality. One-year survival was also analyzed as secondary outcome. Univariate relations between variables and the primary endpoint were assessed by logistic regression analysis. Multiple logistic regression model was built using stepwise backward model after excluding those with $>10 \%$ of missing data. Multiple logistic was repeated including those variables with imputation of missing data without relevant changes (data not shown). The logrank test was used to compare survival among the 4 CIT quartiles. Statistical analysis was performed using the Stata 13.0 package (StataCorp LP, Tx).

\section{Results}

A total of 2977 HT were included in the registry during the study period but 348 were excluded from this study ( 232 age $<16$ years, 57 combined transplantation, 46 retransplantation, and 13 CIT unavailable). The final population of 2629 had a mean age of $53.3 \pm 12.1$ years and 655 women (24.9\%). Mean CIT was $202 \pm 67$ min (minimum $20 \mathrm{~min}$, maximum $600 \mathrm{~min}$ ). Table 1 shows characteristics according to CIT quartile (Table 1). Urgent HT, mechanical ventilation and ventricular assist device were more common in the upper CIT quartiles.

The rate of primary graft failure increased with CIT quartile, and was particularly high in the last quartile (19\% - 22\% - 23\% - 30\%). This was also the case with 1-month (9\% - 12\% - 13\% - 19\%) and 1-year (16\% $19 \%-21 \%$ - 28\%) mortality. Table 2 shows univariate and multivariate logistic regression analysis for 1-month and 1-year mortality (Table 2). CIT was an independent predictor of 1-month mortality (odds ratio [OR] per min 1.00, 95\% confidence interval [CI] 1.00-1.01, $p<.001)$. CIT was also an independent predictor of 1-year mortality (OR per min 1.00, 95\% CI 1.00-1.01, p <.001). Of note, in both cases, the independent influence of CIT in the prognosis was only seen in the last quartile. shows the Kaplan-Meier curves according to CIT quartile.

We found no relevant differences in CIT during the study period (Fig. 2). However, the impact of CIT in 1-month and 1-year mortality decreased with time ( $p$ value for Kruskal-Wallis test to the distribution of ischemic time by year 0.01) (Supplementary Figure), particularly during the last 5 years.

\section{Discussion}

Our main finding is that, although the impact of CIT in HT prognosis seems to be decreasing in the last years, CIT in the last quartile (>246 $\mathrm{min}$ ) is associated with 1-month and 1-year mortality.

The association of CIT with HT prognosis has been previously described [9-12]. However, there still is uncertainty regarding the prognostic effect of CIT and of the cutoff value that might have relevant clinical implications. Some studies have reported no differences in survival even with prolonged CIT $[13,14]$ or have described different cutoffs $[15,16]$.

Our data suggest that we should be concern when ischemic time is longer than $4 \mathrm{~h}$. Del Rizzo et al. also found a clear relation of CIT $>4 \mathrm{~h}$ with mortality, but only in donors $>50$ years [17]. Their small sample 


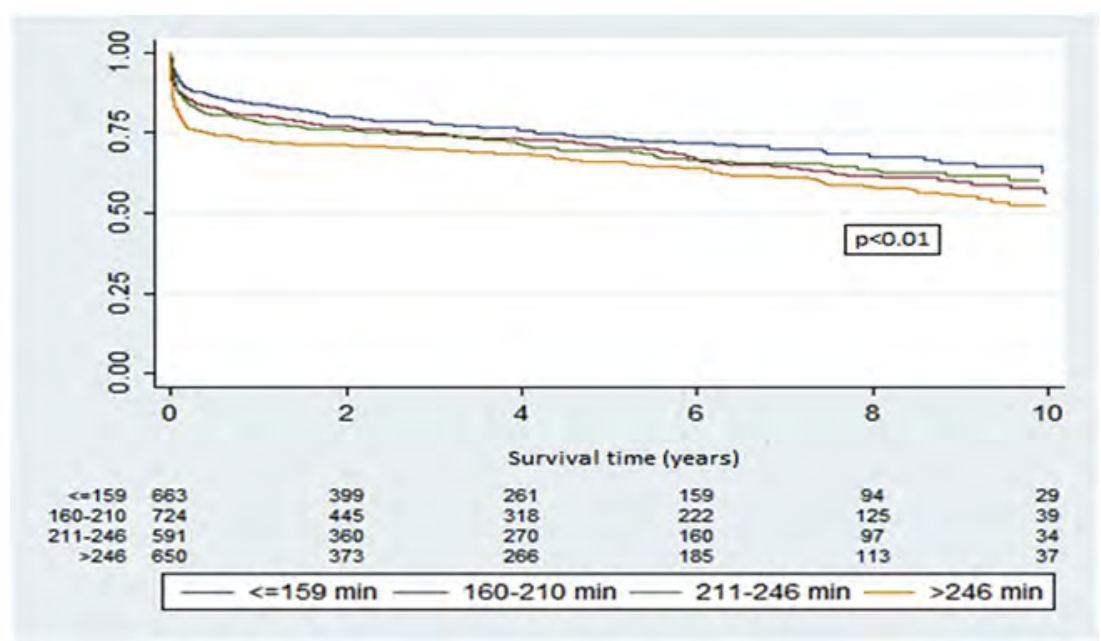

Fig. 1. Kaplan-Meier curves according to cold ischemia time quartile, $p$ value for the log-rank test.

size (only 372) might have been underpowered to detect the prognostic influence with younger donors. In fact, even in children, CIT $>3.5 \mathrm{~h} \mathrm{im-}$ plies an increased risk of graft loss [18]. Reich et al. studied the influence of donor age in CIT prognostic effect [12], under the hypothesis that older donors could be more susceptible to prolonged CIT but found no significant differences. We were also unable to find a specific effect of donor age in CIT prognostic effect.

Two previous single-center studies were unable to find an influence of CIT in the prognosis of HT [13,14]. The first was focused on long-term survival [13] and compared 4 CIT groups ( $<150,150-200,200-250$, $>250 \mathrm{~min}$ ), of note only 80 had CIT $>250 \mathrm{~min}$ and this low number probably limited the power to detect CIT prognostic influence. In fact, the only independent predictor the authors were able to find was recipient female sex. The second study [14] compared $46 \mathrm{HT}$ with CIT $>300 \mathrm{~min}$ with 46 case-matched controls. Although 30-day mortality in patients with CIT $>300$ min was twice that in controls, both groups had a very low 30 -day mortality [ $4.3 \%$ vs. $2.1 \%$ ], compared with our $12.9 \%$. In fact, in that study, only 3 patients died in the 30-day period. One of the strengths of our study is the large number of patients in the upper quartile [650]. Moreover, previous thoracic surgery, that in our study was an independent predictor of mortality, is also associated to longer CIT [19].
Although some authors have described an increase in CIT during a 10 -year period [20], our data do not support this increase. However, the peculiarities of the Spanish National Transplant System [21] might protect our centers from such increase. In any case, our data suggest that the influence of CIT in prognosis is decreasing, as can be seen in the yellow lines depicted in the Supplementary Figure. The reasons why the effect of prolonged CIT might be reduced in the most recent era are unknown. The increasing use of mechanical circulatory support might make recipients in better overall condition at the time of transplant. Also, the better selection of donors, including, when possible, avoiding sex mismatch in male recipients $[22,23]$ might play a role.

Patients in the lower CIT quartile were supported by a ventricular assist device less often than patients in the upper quartile. However, in our registry, ventricular assist device prior to HT was not a risk factor for mortality at 1-month or 1-year after HT, a finding previously described $[24,25]$. In any case, it is clear that patients with prolonged CIT had a greater risk profile. In fact, compared to recipients with shorter CIT, they had more frequently variables that might be associated with a poor prognosis. These variables include not only circulatory support but also prior infection, previous thoracic surgery, urgent transplant,

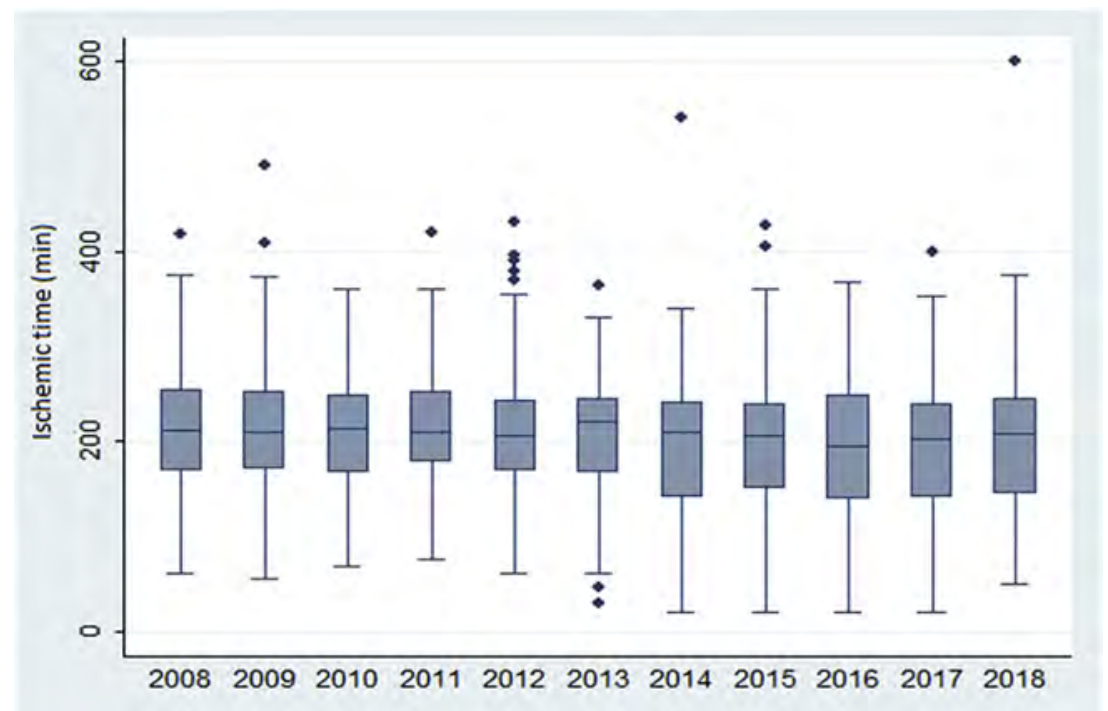

Fig. 2. Cold ischemia time during each year of the study period. 
and mechanical ventilation. All these variables were included in the multivariable analysis. However, it is conceivable that multivariate analysis was not able to correct completely all the differences regarding the risk profile of the four CIT quartiles.

Our study has more limitations. Missing data could have influenced our results. Although in most variables the rate of missing values was extremely low, in some of then, as pulmonary vascular resistance, was higher than $10 \%$. The data came from Spain, with specific patient characteristics and, even more so, logistics, criteria for distribution, and distance from donor to recipient centers. So, the extrapolation of our findings to other health systems should be done with caution. In any case the homogeneity of our National transplant system is also an advantage as decreases the possibility of bias. For instance, in Spain HT after TransMedics ${ }^{\circledR}$ Organ Care System or donation-after-circulatorydeath have not been performed.

In conclusion, although the impact of CIT in HT prognosis seems to be decreasing in the last years, CIT in the last quartile ( $>246 \mathrm{~min})$ is associated with 1-month and 1-year mortality. Our findings suggest the need to limit HT with CIT $>246$ min or to use different myocardial preservation systems if the expected CIT is $>4 \mathrm{~h}$.

Supplementary data to this article can be found online at https://doi. org/10.1016/j.ijcard.2020.06.009.

\section{Authorship contributions}

Conception and design of study: MMS.

Acquisition of data: All.

Analysis and/or interpretation of data: MJVM, MMS.

Drafting the manuscript: MJVM, MMS.

Revising the manuscript critically for important intellectual content: All.

Approval of the version of the manuscript to be: All.

\section{Declaration of Competing Interest}

None.

\section{References}

[1] M.G. Crespo-leiro, M. Metra, L.H. Lund, et al., Advanced heart failure: a position statement of the heart failure Association of the European Society of cardiology, Eur. J. Heart Fail. 20 (2018) 1505-1535.

[2] K.K. Khush, W.S. Cherikh, D.C. Chambers, et al., The international thoracic organ transplant registry of the international society for heart and lung transplantation: thirty-fifth adult heart transplantation report - 2018; focus theme: multiorgan transplantation, J. Hear Lung Transpl. 37 (2018) 1155-1168.

[3] J. Segovia, M.D.G. Cosío, J.M. Barceló, et al., RADIAL: a novel primary graft failure risk score in heart transplantation, J. Hear Lung Transpl. 30 (2011) 644-651.

[4] S.S.A. Singh, J.R. Dalzell, C. Berry, N. Al-Attar, Primary graft dysfunction after heart transplantation: a thorn amongst the roses, Heart Fail. Rev. 24 (2019 Sep) 805-820.
[5] I. Kim, J. Youn, I. Kim, The past, present and future of heart transplantation, Korean Circ. J. 48 (2018) 565-590.

[6] F. González-Vílchez, M. Gómez-Bueno, L. Almenar-Bonet, et al., 28th official report of the spanish society of cardiology Working Group on Heart Failure (1984-2016), Rev. Esp. Cardiol. (Engl Ed) 70 (2017) 1098-1109.

[7] A. Ardehali, F. Esmailian, M. Deng, et al., Ex-vivo perfusion of donor hearts for human heart transplantation (PROCEED II): a prospective, open-label, multicentre, randomised non-inferiority trial, Lancet. 385 (2015) 2577-2584

[8] M.M. Vela, D.G. Sáez, A.R. Simon, Current approaches in retrieval and heart preservation, Ann. Cardiothorac. Surg. 7 (2018) 67-74

[9] Chambers DC, Yusen RD, Cherikh WS, et al. The registry of the international society for heart and lung transplantation: thirty-fourth adult lung and heart-lung transplantation report - 2017; focus theme: allograft ischemic time. J. Hear Lung Transplant. 2017;36:1047-59.

[10] Rossano JW, Cherikh WS, Chambers DC, et al. The registry of the international society for heart and lung transplantation: twentieth pediatric heart transplantation report - 2017; focus theme: allograft ischemic time. J. Hear Lung Transplant. 2017;36: 1060-69.

[11] A. Nicoara, D. Ruffin, M. Cooter, et al., Primary graft dysfunction after heart transplantation: Incidence, trends, and associated risk factors, Am. J. Transpl. 18 (2018) $1461-1470$.

[12] H.J. Reich, J.A. Kobashigawa, T. Aintablian, D. Ramzy, M.M. Kittleson, F. Esmailian, Effects of older donor age and cold ischemic time, Tex. Heart Inst. J. 45 (2018) 17-22.

[13] J.A. Morgan, R. John, A.D. Weinberg, et al., Prolonged donor ischemic time does not adversely affect long-term survival in adult patients undergoing cardiac transplantation, J. Thorac. Cardiovasc. Surg. 126 (2003) 1624-1633.

[14] F.A. Mitropoulos, J. Odim, D. Marelli, et al., Outcome of hearts with cold ischemic time greater than 300 minutes. A case-matched study, Eur. J. Cardiothorac. Surg. 28 (2005) 143-148.

[15] M.E. Currie, Y. Shudo, Y.J. Woo, Successful outcome following orthotopic heart transplantation with a donor half way across the country, Transplant. Proc. 50 (2018) 4062-4063.

[16] R.A. Sorabella, L. Guglielmetti, A. Kantor, et al., Cardiac donor risk factors predictive of short-term heart transplant recipient mortality: an analysis of the united network for organ sharing database, Transplant. Proc. 47 (2015) 2944-2951.

[17] D.F. Del Rizzo, A.H. Menkis, P.W. Pflugfelder, et al., The role of donor age and ischemic time on survival following Orthotopic heart transplantation, J. Hear Lung Transpl. 2498 (1999) 310-319.

[18] M.A. Ford, C.S. Almond, K. Gauvreau, et al., Association of Graft Ischemic Time with survival after heart transplant among children in the United States, J. Hear Lung Transpl. 30 (2011) 1244-1249.

[19] T. Aziz, M. Burgess, A. Rahman, C. Campbell, A. Deiraniya, N. Yonan, Early and longterm results of heart transplantation after previous cardiac surgery, Eur. J. Cardiothorac. Surg. 17 (2000) 349-354.

[20] N.R. Banner, H.L. Thomas, E. Curnow, J.C. Hussey, C.A. Rogers, The importance of cold and warm cardiac ischemia for survival after heart transplantation, Transplantation. 86 (2008) 542-547.

[21] Distribution Criteria of Heart Transplantation. , National Transplant Organization, 2019http://www.ont.es/infesp/CriterioDeDistribucion/Criterios\%20distribuci\%C3\% B3n\%20Coraz\%C3\%B3n\%202019.pdf.

[22] A. Ayesta, G. Urrútia, E. Madrid, et al., Sex-mismatch influence on survival after heart transplantation: a systematic review and meta-analysis of observational studies, Clin. Transpl. 33 (2019), e13737. https://doi.org/10.1111/ctr.13737 (Epub 2019 Nov 10).

[23] M. Martinez-Selles, L. Almenar, M.J. Paniagua-Martin, et al., Donor/recipient sex mismatch and survival after heart transplantation: only an issue in male recipients? An analysis of the Spanish heart transplantation registry, Transpl. Int. 28 (2015) 305-313.

[24] F. Kamdar, R. John, P. Eckman, M. Colvin-Adams, S.J. Shumway, K. Liao, Postcardiac transplant survival in the current era in patients receiving continuous-flow left ventricular assist devices, J. Thorac. Cardiovasc. Surg. 145 (2013) 575-581.

[25] The International Society for Heart and Lung Transplantation, International Thoracic Organ Transplant Registry Data, https://ishltregistries.org/registries/slides.asp 2019 